International Journal of Food Microbiology

Volume 112, Issue 1, 15 October 2006, Pages 51-61
Archimer, archive institutionnelle de l'Ifremer http://www.ifremer.fr/docelec/

http://dx.doi.org/10.1016/j.ijfoodmicro.2006.05.014

(c) 2006 Elsevier B.V. All rights reserved

\title{
Effect of bacterial interactions on the spoilage of cold-smoked salmon
}

\author{
Jean-Jacques Joffraud*, Mireille Cardinal, Josiane Cornet, Jean-Sébastien Chasles, \\ Sandrine Léon, Frédérique Gigout, Françoise Leroi
}

Département Sciences et Techniques Alimentaires Marines, IFREMER, BP 21105, 44311 Nantes, Cedex 3, France

* Corresponding author. Tel: +33 2 40374088; fax: +33 2 40374071; e-mail: joffraud@ifremer.fr

\begin{abstract}
:
Cold-smoked salmon is a lightly preserved fish product in which a mixed microbial flora develops during storage and where the interactive behaviour of micro-organisms may contribute to their growth and spoilage activity. The aim of this study was to assess the effect of the bacterial interactions between the main species contaminating the cold-smoked salmon on bacterial growth, chemical and sensory changes, and spoilage. First, Carnobacterium piscicola, Photobacterium phosphoreum, Lactobacillus sakei, Vibrio sp., Brochothrix thermosphacta and Serratia liquefaciens-like were inoculated as pure cultures on sterile cold-smoked salmon. All bacterial species grew well; Vibrio sp. was the fastest and L. sakei strains developed very rapidly as well with a high maximum cell density on cold-smoked salmon blocks (up to $109 \mathrm{cfu}$ g- 1 after 10 days at $8{ }^{\circ} \mathrm{C}$ ). Based on sensory analysis, Vibrio sp. was identified as non-spoilage bacteria, C. piscicola as very lightly and B. thermosphacta as lightly spoiling. L. sakei and S. liquefaciens-like were found to be the most spoiling bacteria. Secondly, C. piscicola and L. sakei, two species frequently occurring in the lactic flora of the product, were inoculated together and each of them in mixed cultures with respectively P. phosphoreum, Vibrio sp., B. thermosphacta, and S. liquefaciens-like. The growth of L. sakei was shown to strongly inhibit most of the co-inoculated strains i.e. P. phosphoreum, B. thermosphacta, S. liquefaciens-like and, to a lesser extent, Vibrio sp. The growth of C. piscicola seemed to be enhanced with B. thermosphacta and to develop earlier with $\mathrm{P}$. phosphoreum and Vibrio sp. Conversely, S. liquefaciens-like and $\mathrm{P}$. phosphoreum were weakly inhibited by $\mathrm{C}$. piscicola. The main observation resulting from the sensory evaluation was the delay in the appearance of the spoilage characteristics in the mixed cultures with $\mathrm{L}$. sakei, in particular L. sakei/ S. liquefaciens-like. On the other hand, the spoilage activity of the nonspoiler strains Vibrio sp. or the moderate spoilage strains B. thermosphacta and C. piscicola was increased when they were associated together.
\end{abstract}

It is concluded that the spoilage behaviour of micro-organisms in mixed culture is significantly different from pure culture and explain the difficulty to find robust quality indices for this product.

Keywords: Cold-smoked salmon; Microbial flora; Interaction; Spoilage 


\section{Introduction}

Vacuum-packed cold-smoked salmon (CSS) is of considerable economic importance worldwide, and particularly in Europe. This foodstuff is produced by a light salting and smoking process and is typically consumed as ready-to-eat with no heat treatment. CSS, usually stored at chilled temperature, is very sensitive to deterioration and, based on sensory evaluation, has a limited shelf life ranging from 3 to 6 weeks at $5^{\circ} \mathrm{C}$ (Ward, 2001). Microbial activity has been found to be responsible for off-flavours (Truelstrup Hansen et al., 1995; Truelstrup Hansen et al., 1996; Joffraud et al., 1998; Leroi et al., 2001). In recent years, the specific bacterial flora of CSS or cold-smoked trout have been extensively studied and the main taxonomic groups that occur frequently and dominate the spoilage microflora have been determined (Truelstrup Hansen et al., 1995; Gram and Huss, 1996; Leroi et al., 1998; Lyhs et al., 1998; Paludan-Müller et al., 1998; Truelstrup Hansen et al., 1998; Truelstrup Hansen and Huss, 1998; Jorgensen et al., 2000a; Leroi et al., 2000b; Leroi et al., 2001; GonzalezRodriguez et al., 2002). Moreover, with the aim of identifying specific spoilage organisms (SSOs), the spoilage potential of bacteria belonging to these different taxonomic groups isolated from CSS by Leroi et al. (1998) was assessed by investigating off-odour production from inoculated CSS using sensory analysis at the end of storage (Stohr et al., 2001) and by analyzing the composition of the volatiles released (Joffraud et al., 2001; Jorgensen et al., 2001). These inoculation studies allowed some bacterial species to be characterized as active spoilers when inoculated in single culture into sterile CSS blocks. Thus, Lactobacillus sakei, Brochothrix thermosphacta, Photobacterium phosphoreum, Aeromonas spp. and Serratia liquefaciens-like were found to produce specific off-odours/flavours associated with CSS spoilage (Stohr et al., 2001). However, large variations in the quantitative and qualitative microbiological composition of commercial products have previously been observed (Truelstrup Hansen et al., 1998; Truelstrup Hansen and Huss, 1998; Jorgensen et al., 2000a; Jorgensen et al., 2000b; Leroi et al., 2001; Cardinal et al., 2004). As a result, several frequently occurring situations have been described: domination by lactic acid bacteria (LAB), Carnobacterium sp. and/or Lactobacillus sp., at levels of $10^{7}-10^{9} \mathrm{cfu} \mathrm{g}^{-1}$; domination by a mixture of $\mathrm{LAB}$ and Enterobacteriaceae at levels of $10^{7}-10^{8} \mathrm{cfu}^{-1}$; domination by Photobacterium / marine Vibrio-type at levels of $10^{6}-10^{7} \mathrm{cfu} \mathrm{g}^{-1}$ occasionally with high levels of LAB; domination by a mixture of total LAB and B. thermosphacta. Under these conditions, interactions between dominating bacterial species may play an important role in sensory spoilage.

In the present study, in order to investigate the interactions, sterile CSS blocks were inoculated with mixed cultures in pairs combining the two main LAB occurring on commercial CSS, L. sakei and C. piscicola, together and each one of them with $B$. thermosphacta, S. liquefaciens-like, P. phosphoreum and Vibrio sp. respectively.

Contrary to previous studies where samples inoculated with single bacterial cultures were analysed for sensory changes and volatile production only at the end of the storage period (Joffraud et al., 2001; Stohr et al., 2001), the aim of the present work was to investigate chemical, bacterial and sensory changes over the whole storage period to provide a kinetic insight and to examine the interactions between predominating species. 


\section{Materials and Methods}

\subsection{Sterile CSS model}

$58 \mathrm{~kg}$ of sterile CSS model system produced in two batches by an aseptic process and ionization as described by Joffraud et al. (1998) was used as substrate. In this process, CSS was diced into approximately 5-mm-sided cubes, vacuum-packed and frozen at $-80^{\circ} \mathrm{C}$ before the ionization treatment. Based on three determinations, the composition of this model system was $60.4 \% \pm 0.8$ water, $4.4 \% \pm 0.3 \mathrm{NaCl}$ in water phase and $0.82 \mathrm{mg}^{100 \mathrm{~g}^{-1} \pm 0.14}$ phenols for the trial 1 and $61.6 \% \pm 0.9$ water, $4.8 \% \pm 0.4 \mathrm{NaCl}$ in water phase, $0.88 \mathrm{mg} 100$ $\mathrm{g}^{-1} \pm 0.16$ for the trial 2 .

\subsection{Bacterial strains}

Strains, selected from the collection of the laboratory, were previously isolated from vacuum-packed CSS and identified (Leroi et al., 1998). Two inoculation trials were performed at different periods and each trial was divided into two successive sets. The different strains inoculated in these trials and the corresponding labels used in graphs are shown in Table 1. The first two sets (A and C) of each trial used pure cultures from $C$. piscicola, P. phosphoreum, L. sakei, Vibrio sp., B. thermosphacta and S. liquefaciens-like. Except for the two isolates for $C$. piscicola, each group was represented by a mixture of five strains. All isolates, apart from Vibrio sp, had already been individually tested for spoilage potential in a previous study (Stohr et al., 2001). The second sets (B and D) consisted of mixed cultures in pairs, combining $L$. sakei and $C$. piscicola together and each one of them with $B$. thermosphacta, S. liquefaciens-like, P. phosphoreum and Vibrio sp. respectively (Table 1).

\subsection{Culture, sample inoculation and packaging}

Bacterial strains were revived from frozen storage by inoculation of a loop full into $10 \mathrm{ml}$ of appropriate culture medium. C. piscicola strains were grown in Elliker broth (Elliker et al., 1956) (Biokar Diagnostics, Beauvais, France), L. sakei in Man, Rogosa and Sharpe (MRS) broth (de Man et al., 1960) (Merck, Darmstadt, Germany), and the other strains in brain-heart infusion (BHI) (Difco Laboratories, Detroit, MI, USA). Strains were pre-cultured individually at $20^{\circ} \mathrm{C}$, except for $P$. phosphoreum and Vibrio sp. $\left(15^{\circ} \mathrm{C}\right)$, for $24-48$ hours and then cultured in the same conditions until an absorbance-estimated concentration level of approx. $10^{8}$ cells $\mathrm{ml}^{-1}$ was achieved. Isolates belonging to the same genus or species were mixed; for combinations, the mixtures of two taxonomic groups were pooled; the final mixture was thousand fold diluted in cooled sterile peptone water $(0.85 \% \mathrm{NaCl}$ and $0.1 \%$ peptone). To achieve an inoculation concentration of approx. $10^{3}-10^{4}$ cells $\mathrm{g}^{-1}, 6 \mathrm{ml}$ of culture dilution (around $10^{5}$ cells $\mathrm{ml}^{-1}$ ) was added to $300 \mathrm{~g}$ of sterile CSS blocks in a sterile plastic bag, followed by a careful manual mixing of the bag contents. This action was repeated eight times until the amount needed was achieved (300g x 8) for each bacterial group tested, alone or in combination. For each set, a control was created by replacing the inoculum with sterile peptone water. Blocks were then allotted and vacuum-packed in polyamide/polyethylene bags (PA/PE 20/70, Euralpac, Alfo, Germany). Permeability of the packaging film was $40-50 \mathrm{~cm}^{3}$ / $\mathrm{m}^{2}$ for $\mathrm{O}_{2}$ and $146 \mathrm{~cm}^{3} / \mathrm{m}^{2}$ for $\mathrm{CO}_{2}$ at $24 \mathrm{~h}\left(1 \mathrm{~atm}\right.$ at $\left.23^{\circ} \mathrm{C}, 75 \% \mathrm{r} . \mathrm{F}\right)$. Bag weight differed depending on the type of analysis (20 $\mathrm{g}$ for sensory analysis and $60 \mathrm{~g}$ for microbial and chemical analysis). Despite French regulations prescribing a storage temperature range of 0-4 ${ }^{\circ} \mathrm{C}$ for chilled CSS (AFNOR 1997), $8^{\circ} \mathrm{C}$ was chosen to mimic temperature abuse at different 
stages from production to consumption (transport, commercial and domestic refrigeration, etc.). Immediately after inoculation and then twice a week for 5-6 weeks, bags from each batch (i.e. each taxonomic group or combination) were opened for sensory, microbiological and chemical analysis.

\subsection{Quantitative microbiological analysis}

Twice a week, inoculated strains were enumerated by a direct plating technique. Flesh samples (15 g) were homogenized with $60 \mathrm{ml}$ of chilled peptone water in a stomacher bag filter for 2 min using a stomacher 400 (Lab Blender, London, UK) and left at room temperature for $30 \mathrm{~min}$ for resuscitation. The homogenate was serially diluted 10-fold in chilled peptone water and $0.1 \mathrm{ml}$ of each appropriate dilution was spread on duplicate petri plates. When inoculated in pure culture, enumeration of strains was performed by using the following media: plate count agar (PCA; Biokar) incubated aerobically for $3-5$ days at $20^{\circ} \mathrm{C}$ for $B$. thermosphacta and S. liquefaciens-like; Long and Hammer's medium containing $1 \%$ $\mathrm{NaCl}$ (van Spreekens, 1974) after 5 days of aerobic incubation at $15^{\circ} \mathrm{C}$ for $P$. phosphoreum and Vibrio sp.; MRS agar (Merck) for L. sakei and Elliker broth (Biokar) with 1.5\% of agar for C. piscicola, MRS and Elliker plates were both placed in anaerobic jars $\left(20 \% \mathrm{CO}_{2}, 80 \%\right.$ $\mathrm{N}_{2}$ ) with Anaerocult A (Merck) at $20^{\circ} \mathrm{C}$ for 5 days. For strains inoculated in combination, $L$. sakei, B. thermosphacta and S. liquefaciens-like were selectively enumerated by means of suitable media. Spread plates of Rogosa agar (Biokar) incubated anaerobically at $20^{\circ} \mathrm{C}$ for $\mathrm{L}$. sakei, Streptomycin Thallium Acetate Actidion (STAA) (Gardner, 1980) (2\% peptone, 0.2\% yeast extract, $0.1 \% \mathrm{KH}_{2} \mathrm{PO}_{4}, 0.1 \% \mathrm{MgSO}_{4} \quad 7 \mathrm{H}_{2} \mathrm{O}$, $1.5 \%$ glycerol, $1.3 \%$ agar, $0.05 \%$ streptomycin, $0.005 \%$ cycloheximide and $0.005 \%$ thallium acetate) incubated at $20^{\circ} \mathrm{C}$ for $\mathrm{B}$. thermosphacta and pour plates of CASO agar (Merck) overlaid by Violet Red Bile Glucose agar (VRBG; Oxoid, Basingstoke, England) incubated at $30^{\circ} \mathrm{C}$ for 2 days for S. liquefacienslike. $P$. phosphoreum and Vibrio sp. were differentially counted on Long and Hammer's medium on the basis of colony size, colonies of $L$. sakei or C. piscicola being smaller. In combination with $P$. phosphoreum or Vibrio sp., $C$. piscicola was selectively enumerated on Elliker plates.

\subsection{Chemical analysis}

The remaining flesh in the bags opened for microbiological analysis was homogenized in a Waring Blender (New Hartford, CO, USA). Total volatile basic nitrogen (TVBN) and trimethylamine (TMA) were measured in duplicate by the Conway microdiffusion method (Conway and Byrne, 1933). The $\mathrm{pH}$ value was measured in the fivefold-diluted flesh with a pH meter (Mettler Delta 320, AES, Combourg, France).

\subsection{Sensory analysis}

A trained panel of 6 people experienced in smoked salmon evaluation (IFREMER), was required to smell each sample and to identify, among an established list of seven descriptors (Table 2), the main detected odour. Before starting the experiment, the panel was trained during six sessions with aromatic molecules, either in a water solution or added to smoked salmon blocks, to recognize the odours of spoiled CSS. These molecules have previously been identified in CSS as related to odours of spoiled products (Joffraud et al., 2001; Stohr et al., 2001). Samples of a same set were evaluated twice a week, for 31 days in the first trial and for 42 days in the second trial (see Table 1). Sessions were performed in individual partitioned booths, as described in the procedure NF V-09-105 (AFNOR, 1987) and equipped 
with a computerised system (Fizz, Biosystèmes, Couternon, France). Products were assigned 3-digit numbers, randomised and served simultaneously after 15 min at room temperature. 20 $\mathrm{g}$ of blocks of CSS was used for each sample and each panellist. Before testing, each assessor opened the packaging himself. Assessors identified the main odour criteria by ticking the appropriate descriptor and, at the end of the evaluation, panellists classified each sample according to the spoilage level (NS: non-spoiled; LS: lightly spoiled; SS: strongly spoiled).

\subsection{Statistical analysis}

Quotation frequencies obtained from the panel for each sensory criteria (spoilage level and main odour) allowed correspondence factorial analysis (CFA) on Uniwin software (Uniwin Plus, version 3, Sigma Plus), respectively for single cultures and mixed cultures.

\section{Results}

\subsection{Pure cultures}

\subsubsection{Bacterial kinetics}

Fig. $1 \mathrm{~A}$ and $\mathrm{B}$ show the growth patterns of the different groups of bacteria as pure cultures during vacuum storage at $8^{\circ} \mathrm{C}$ performed in the two trials. Samples inoculated with $P$. phosphoreum in the second period were found to be contaminated so these results will not be shown further or commented on. Most of the cultures were inoculated in a range of $10^{3}-10^{4}$ $\mathrm{cfu} \mathrm{g}^{-1}$ except for Vibrio sp. in the two trials and C. piscicola in the second one, inoculated at $10^{4}-10^{5}$ cfu g $^{-1}$. All bacterial species grew well on the sterile CSS model. They reached their maximum level after 1 to 2 weeks of storage with final counts ranging between $10^{7} \mathrm{cfu} \mathrm{g}^{-1}$ and $10^{9} \mathrm{cfu} \mathrm{g}^{-1}$. The number of $L$. sakei increased rapidly and reached $10^{9} \mathrm{cfu} \mathrm{g}^{-1}$ after 10 days. Vibrio sp. had quite the same growth rate, attaining its maximum level between 3 and 7 days depending on the trial. However, although inoculated at higher level than $L$. sakei, the maximum level $\left(10^{8} \mathrm{cfu} \mathrm{g}^{-1}\right)$ was always $1 \log$ lower than for $L$. sakei. The growth of the other species was slower (Fig. 1A), reaching $10^{7-8} \mathrm{cfu} \mathrm{g}^{-1}$ after 2 or 3 weeks of storage. No colony was detected on petri plates regarding control samples throughout the storage so they were considered as sterile.

\subsubsection{Chemical changes}

TVBN concentration in the controls of both trials did not exceed $20 \mathrm{mg}-\mathrm{N} 100 \mathrm{~g}^{-1}$. Most of the bacterial groups produced a significant amount of TVBN except $B$. thermosphacta and $C$. piscicola (Fig. 2 A,B). In the first trial, concentration increased from 17-18 to 55-56 mg-N $100 \mathrm{~g}^{-1}$ for $L$. sakei and Vibrio sp. and from 4 to 37 and $40 \mathrm{mg}-\mathrm{N} 100 \mathrm{~g}^{-1}$ respectively in the second trial. In the first trial, two patterns could be observed in the production of TVBN. The maximum production rate was exhibited during the first two weeks for $P$. phosphoreum and Vibrio sp. and during the last two weeks for $L$. sakei and S. liquefaciens-like. This observation was confirmed by the data obtained in the second trial with L. sakei and Vibrio sp.

TVBN production is correlated with cell numbers during bacterial growth. Thus, the apparent yield factor proposed by Dalgaard (1995) for production of TVBN by the different bacterial groups in pure culture has been calculated. $p \mathrm{Y}_{\text {TVBN/CFU }}=-\log \left(\mathrm{TVBN}_{\text {final }}-\mathrm{TVBN}\right.$ initial $/ C F U_{\text {final }}-\mathrm{CFU}_{\text {initial }}$ ) where $\mathrm{CFU}$ initial are the initial cell concentrations and $\mathrm{CFU}$ final (cfu 
$\mathrm{g}^{-1}$ ) are the cell concentrations at the end of the exponential growth phase, TVBN initial and TVBN final are the initial amount of TVBN and the amount of TVBN at the end of the exponential growth phase. Based on $p \mathrm{Y}$ TVBN/CFu, $P$. phosphoreum was found to be the strongest producer of TVBN with $6.1 \mathrm{log}\left(\mathrm{mg}-\mathrm{N}\right.$ TVBN $\left.\mathrm{cfu}^{-1}\right)$ followed by Vibrio sp. (6.7), $S$. liquefaciens-like (6.9) and L. sakei (7.8).

Only Vibrio sp., P. phosphoreum and S. liquefaciens-like produced TMA; concentrations increased from 2 to $20-23$ mg-N $100 \mathrm{~g}^{-1}$ in the first trial (data not shown). The $\mathrm{pH}$ was fairly stable during storage, ranging from 6.10 to 6.30 except for $L$. sakei, which showed a decrease from 6.13 to 5.73. This drop in $\mathrm{pH}$ in samples inoculated with $L$. sakei was confirmed in the second period, when the $\mathrm{pH}$ decreased from 6.13 to 5.63 .

\subsubsection{Sensory changes}

Correspondence factorial analysis (CFA) performed on the seven sensory descriptors and the three levels of spoilage allowed the separation, on the first axis, of strongly spoiled samples (right part of the Fig. 3) from non-spoiled and lightly spoiled samples (left part of the Fig. 3). The first axis restored $40.4 \%$ of the total information and was a "spoilage axis" separating the strongly spoiled samples from the others. Non-spoiled (upper part) and lightly spoiled samples (lower part) were discriminated on the second axis $(14.5 \%$ of the information). Three different evolution patterns were observed according to the strains. Control samples were located in the area of non-spoiled samples with no specific odour apart from smoke and salmon notes, except for a slight grassy note at the end of the storage period. Vibrio sp. and C. piscicola had characteristics similar to the control samples and presented a limited spoilage level during storage. Vibrio sp. was mainly classified in the non-spoiled group, even though a light amine note was detected, whereas $C$. piscicola presented grassy and fruity notes and samples were identified as lightly spoiled after three weeks of storage. $P$. phosphoreum and $B$. thermosphacta constituted the second group of bacteria. These strains developed some notes of spoilage during storage and reached a level of light spoilage more rapidly than the previous group. Their main odour characteristics were amine and feet notes. The third group identified according to the spoilage intensity included $L$. sakei and $S$. liquefaciens-like. These two bacteria were the most spoiling micro-organisms and were classified, very early, in the strong spoilage category. After three weeks of storage for $S$. liquefaciens-like and only ten days for L. sakei, samples were rejected by the panel. At this moment, more than $50 \%$ of the panellists classified samples in the category "strong spoilage". Odours were described as amine and sulphur notes.

\section{2. Mixed cultures}

\section{2. 1. Bacterial kinetics}

\section{Combination L. sakei / other species}

Fig. 4 presents the growth kinetics of $L$. sakei when inoculated in mixed cultures with respectively C. piscicola, B. thermosphacta, S. liquefaciens-like, $P$. phosphoreum and Vibrio sp. Growth of $L$. sakei strains did not seem to be affected by the other co-inoculated strains in comparison with growth in pure culture. Conversely, growth of $B$. thermosphacta, $S$. liquefaciens-like, P. phosphoreum and Vibrio sp. was clearly inhibited by L. sakei. It was not possible to know the specific growth of $C$. piscicola because an efficient selective medium was not available. A Cresol Red Thallium Acetate Sucrose Inulin medium proposed by Wasney et al. (2001) was unsuccessfully tested (this medium underestimated the number of 
Carnobacteria in pure culture when compared to a less selective medium such as Elliker, data not shown). The difference in growth level between pure and mixed culture mostly occurred after 15 days of storage when $L$. sakei had reached its maximum level. The differential was about 3 log except for Vibrio sp., which showed a weaker inhibition of growth (around $1 \log$ ).

\section{Combination C. piscicola / other species}

Fig. 5 represents the growth kinetics of the different bacterial groups in combination with C. piscicola. B. thermosphacta growth was not affected by the presence of C. piscicola (Fig. 5A) whereas a weak inhibition $(1 \mathrm{log})$ was observed for $S$. liquefaciens-like and $P$. phosphoreum and less clearly for Vibrio sp.. On the other hand, the growth of $C$. piscicola seemed to be lightly enhanced by the presence of B. thermosphacta, P. phosphoreum and Vibrio sp. but unchanged with S. liquefaciens-like.

\section{2. 2. Chemical changes}

\section{TVBN production - Combination L. sakei / other species}

When inoculated with non-TVBN-producing strains C. piscicola or B. thermosphacta, $L$. sakei produced TVBN at approximately the same level as in pure culture (55 mg-N $100 \mathrm{~g}^{-1}$ ). In pure culture, the amount of TVBN generated by $S$. liquefaciens-like, $P$. phosphoreum and Vibrio sp. was in the same range as $L$. sakei $\left(40-55 \mathrm{mg}-\mathrm{N} 100 \mathrm{~g}^{-1}\right)$. This level was hardly reached in the mixed culture $L$. sakei / S. liquefaciens-like (40 mg-N $100 \mathrm{~g}^{-1}$ ) but was much higher in L. sakei / Vibrio sp. (60 mg-N 100g $\mathrm{g}^{-1}$ ). TVBN production generated by the mixed culture L. sakei / P. phosphoreum followed the same pattern as $P$. phosphoreum in pure culture.

TVBN production - Combination C. piscicola / other species

C. piscicola strains used in our study did not produce TVBN in pure culture. In combination with another non-TVBN-producing species (B. thermosphacta), a significant amount was found ( $40 \mathrm{mg}-\mathrm{N} 100 \mathrm{~g}^{-1}$ ) only at the end of storage. When inoculated with TVBNproducing species in pure culture (S. liquefaciens-like, $P$. phosphoreum and Vibrio sp.), 3 situations could be observed: (i) the final level in mixed culture remained unchanged as in pure culture ( $P$. phosphoreum, $L$. sakei whose results have been described previously), (ii) the final level was higher (56 mg-N $100 \mathrm{~g}^{-1}$ ) (Vibrio sp.), (iii) the final level was lower (27 mg-N $100 \mathrm{~g}^{-1}$ ) ( S. liquefaciens-like).

\section{TMA production and $\mathrm{pH}$ changes}

Production of TMA by S. liquefaciens-like was inhibited in mixed cultures with $L$. sakei or C. piscicola which are non-TMA-producing in pure cultures. The amount of TMA generated by Vibrio sp. was identical in pure culture and in mixed cultures with the two LAB species. $P$. phosphoreum produced the same level of TMA in pure culture and in mixed culture with $C$. piscicola (16 mg-N $\left.100 \mathrm{~g}^{-1}\right)$ but this level was reduced in mixed culture with L. sakei (18 mg$\mathrm{N} 100 \mathrm{~g}^{-1}$ versus 23 mg-N $100 \mathrm{~g}^{-1}$ )

$\mathrm{pH}$ evolution in mixed cultures containing $L$. sakei showed the same pattern as $L$. sakei in pure culture i.e. a slight acidification (data not shown). For mixed cultures with C. piscicola, no change of $\mathrm{pH}$ was noted compared to the pure cultures except for the combination with $B$. thermosphacta where the $\mathrm{pH}$ dropped (from 6.10 to 5.70) at the end of the storage period. 


\subsubsection{Sensory changes}

CFA performed on the frequencies of perception of the sensory characteristics and the three levels of spoilage, obtained for the mixed cultures, gave the same kind of representation as for pure cultures. The first axis of Fig. 6 allowed the spoilage evolution of each association of bacteria to be followed, from non-spoiled samples to strongly spoiled samples. However, new developments regarding the spoilage during storage at $+8^{\circ} \mathrm{C}$ appeared in some cases, when strains belonging to different species were associated together. When the most spoiling strains were simultaneously in culture (L. sakei / S. liquefaciens-like), an interaction was observed regarding the spoilage level since the classification in the strong spoilage group was delayed. Samples were only classified in the stronger spoilage group after four weeks whereas $L$. sakei in pure culture reached the same level in ten days and S. liquefaciens-like in three weeks. The association of the spoiler strains of $L$. sakei with the moderate spoilage activity strains, such as $P$. phosphoreum and $B$. thermosphacta, the very lightly spoiling strains of $C$. piscicola or the non-spoiler strains of Vibrio $s p$. led to two different evolution patterns: either a decrease in the spoilage power or an effect similar to the strongest spoiler strain. Cultures $L$. sakei / C. piscicola, L. sakei / P. phosphoreum or L. sakei / B. thermosphacta reduced the effect of L. sakei on spoilage, delaying both the appearance of spoilage descriptors and the moment when samples were detected as strongly spoiled. In contrast, samples inoculated with the associations L. sakei / Vibrio sp. were as spoiled as when inoculated with $L$. sakei alone. Samples kept the same strong spoilage characteristics, described as sulphur and amine notes. When two non-spoiler, very light or moderate spoiler strains were associated, such as $C$. piscicola / Vibrio sp., C. piscicola / B. thermosphacta or C. piscicola / P. phosphoreum, the spoilage either followed the same evolution during the storage as in pure culture (C. piscicola / $P$. phosphoreum) or, conversely, increased as observed with the mixed culture, C. piscicola / Vibrio sp. and the culture C. piscicola / B. thermosphacta. In this latter case, samples became highly spoiled after 24 days whereas they never reached this level of spoilage in pure culture. When C. piscicola was co-inoculated with the strong spoiler strains of S. liquefaciens-like, samples exhibit the same sensory characteristics as when inoculated with S. liquefaciens-like alone

\section{Discussion}

Some results obtained in this study confirm the findings of previous works performed in the field of CSS quality, shelf life and spoilage. The rapid growth of L. sakei strains on CSS has already been reported in previous studies (Jorgensen et al., 2000a; Joffraud et al., 2001; Stohr et al., 2001). The five strains of each group had shown an heterogeneous spoilage potential when individually tested by Stohr et al., (2001). In this study, sensory changes assigned to each group and resulting from the interaction of the five mixed strains corresponded to the spoilage potential of the strongest spoiling strains except for $B$. thermospacta and $P$. phosphoreum, classified as weak spoiling group in our study whereas some strains were found to be strongly spoiling in the previous study. For S. liquefaciens-like and $L$. sakei, the inoculated products were rejected just after the exponential stage and at the beginning of the stationary phase of the growth curves. This behaviour was described by Gram and Huss (1996) as typical of SSOs. These findings are not completely in agreement with those of Jorgensen et al. (2000a). Based on biogenic amines production, shown to correlate closely with sensory scores of sliced CSS (Jorgensen et al., 2000b), they concluded that $P$. phosphoreum was the main specific spoilage organism in CSS whereas S. liquefacienslike, although part of the spoilage microflora, was not able individually to deteriorate the product. The production of metabolites leading to spoilage has been shown to be often straindependent (Jorgensen et al., 2000a, Stohr et al., 2001) and can explain such a discrepancy. 
The spoilage potential of Vibrio sp. in CSS had never been tested previously. Although this species is suspected to be frequently present in this product (Bourrain et al., 2000; Cardinal et al., 2004), it is not responsible for any off-odours' production. Similar results were obtained for $C$. piscicola, which confirm the potential interest of this LAB species for a biopreservation application, currently tested by different research teams (Yamazaki et al., 2003; Brillet et al., 2004; Nilson et al., 2005; Vaz-Velho et al., 2005). Results from pure cultures also allowed us to confirm that TVBN alone is not a good indicator for estimation of the sensory spoilage. Indeed, Vibrio sp. produced a significant amount of TVBN (40-45 mg-N $100 \mathrm{~g}^{-1}$ ) although no off-odour was detected. TVBN had been shown to be a useful quality index for naturally contaminated CSS only when associated to the count of Lactobacillus on Rogosa agar (Leroi et al., 2001).

This work has displayed some evidence of interaction between inoculated strains in terms of growth patterns, chemical changes and sensory evolution.

Combination L. sakei/other groups

Inhibition of $P$. phosphoreum and Enterobacteriaceae co-inoculated with Lactobacillus sakei has already been mentioned by Jorgensen et al. (2000a). TVBN concentrations in cocultures involving $L$. sakei strains and TVBN-producing bacteria (Vibrio sp., P. phosphoreum and $S$. liquefaciens-like) were lower than the addition of TVBN produced by both the single cultures. This observation cannot be explained only by the growth inhibition of the coinoculated strains by $L$. sakei. Indeed, except for L. sakei/ S. liquefaciens-like, TVBN production observed in the mixed culture did not correspond to the addition of the predicted TVBN production by the two groups when using the yield factors (data not shown). Regarding the sensory evolution, the main observation resulting from our experiments is the delay in the appearance of the spoilage characteristics in most mixed cultures with L. sakei, in particular samples inoculated with $L$. sakei/S. liquefaciens-like which are the greatest spoilers when cultivated alone. Based on biogenic amine production, Jorgensen et al. (2000a) showed, on the contrary, that $L$. sakei enhanced the spoilage activity of S. liquefaciens-like. Surprisingly, the association with $C$. piscicola did not provide a stronger inhibition of spoilage than with the other groups. However, some strains of $C$. piscicola which have been selected for their capacity to inhibit Listeria monocytogenes are also active against Lactobacillus strains (Duffes et al., 1999 ; Brillet et al., 2005).

Combination C. piscicola/other groups

When inoculated in pure culture, C. piscicola strains exhibited good growth, did not produce any TVBN nor TMA, did not modify the $\mathrm{pH}$ and hardly spoiled the product only after three weeks of storage. In mixed cultures, C. piscicola grew very well too. Growth was even enhanced with $B$. thermosphacta or developed earlier with $P$. phosphoreum and Vibrio sp. While B. thermosphacta, Vibrio sp. and L. sakei growth was unaffected by the presence of C. piscicola, S. liquefaciens-like and $P$. phosphoreum were weakly inhibited and a limited suppression of the cell count within one log was observed. Jorgensen et al. (2000a) have also observed an inhibition of $P$. phosphoreum and Enterobacteriaceae by $C$. divergens. The influence of $C$. piscicola on TVBN production in the different associations varied according to the strains. Although $C$. piscicola and B. thermosphacta did not produce TVBN in single culture, a slight production was observed when they were inoculated together. The TVBN production in the association with Vibrio sp. was also higher than that in the pure culture. In a previous study, Brillet et al. (2005) had shown that $C$. piscicola (different strains than in the present work) did not produce TVBN when inoculated in pure culture in sterile CSS blocks ; however, when inoculated in naturally contaminated products, TVBN production was significantly enhanced. This phenomenon could be explained by the presence of Brochothrix and/or Vibrio in the naturally contaminated product. In association with S. liquefaciens-like, the production of TVBN was totally suppressed that could be imputed, based on yield factor, 
to the partial inhibition of growth of these bacteria. The $\mathrm{pH}$ drop in samples with $C$. piscicola /B. thermosphacta was surprising as none of the strains acidified the product in pure culture and as a stimulation of the TVBN production was observed which should have had the opposite effect. The main observation resulting from our experiments concerning the sensory evaluation was that the spoilage potential of $C$. piscicola was increased when associated together with the non-spoiler group Vibrio sp. or with the moderate spoiler group $B$. thermosphacta. This is in concordance with the increase of TVBN observed in both cases.

An understanding of the microbial ecology is essential for the development of preservation techniques aimed at reducing excessive food losses. Identifying the specific spoilage organisms of lightly preserved fish products such as CSS has proved difficult (Gram et al., 2002) probably because different groups of bacteria are involved under different conditions. As reviewed by Gram et al. (2002), substrate base, nutrient composition, chemical and physical parameters are very important for the selection, growth and activity of spoilage micro-organisms. Moreover, microbial food spoilage occurs when micro-organisms reach a high level $\left(10^{7}-10^{9} \mathrm{cfu} \mathrm{g}^{-1}\right)$ and at this level the micro-organisms are thought to interact by influencing the growth of one another (Gram et al., 2002; Malakar et al., 2003). Thus, interactive behaviour between the micro-organisms determines selection and metabolism and subsequently renders the understanding of spoilage mechanisms even more difficult. Malakar et al. (1999) stated that, in non fermented products, microbial interactions could be neglected because concentrations of micro-organisms are generally low and a high level indicates that spoilage has already occurred. The case of CSS seems to be different ; indeed, it has been shown many times that a high level of micro-organisms does not always lead to spoilage (Truelstrup Hansen et al., 1996; Truelstrup Hansen and Huss, 1998; Truelstrup Hansen et al., 1998; Leroi and Joffraud, 2000a; Leroi et al., 2001). Thus, interactions between the main groups of micro-organisms developing in CSS should be taken into account to better explain the spoilage process and to predict the shelf life and safety of the products.

The aim of our study was to point out the main interactions between the major components of the bacterial flora and not to elucidate the mechanisms of these interactions. However, some hypotheses can be suggested. As reviewed by Gram et al. (2002), several types of interaction have been described in food ecosystems, including antagonistic or cooperative behaviour. Competition for nutrients is considered to be one of the major causes of interaction amongst bacteria and may select for the organisms best capable of using the limiting compounds. Such mechanisms could be involved in the mixed cultures C. piscicola/S. liquefaciens-like and $C$. piscicola/P. phosphoreum. Changes in environmental conditions, such as lowering the $\mathrm{pH}$, can be a powerful way to create a selective advantage and thus to antagonize other bacteria. This is probably the case of co-cultures involving $L$. sakei that decreased the $\mathrm{pH}$ from 6.2 to 5.6-5.7 leading to the inhibition of the co-inoculated species. On the other hand, cooperative behaviour, where the growth or a particular metabolism of one organism is favoured by the growth of another organism, seemed to be the cause of the growth enhancement of $C$. piscicola co-inoculated with $B$. thermosphacta, $P$. phosphoreum or Vibrio sp. This behaviour could be compared to metabiosis (interspecies microbial metabolism of arginine) described by Jorgensen et al. (2000a) where production of putrescine was strongly enhanced when cultures of S. liquefaciens-like or Hafnia alvei were grown with C. divergens or L. sakei.

The present study has contributed to characterise the spoilage potential of different bacterial associations and the three possible scenarios (enhancement, decrease or no effect) have been observed and are summarised in Table 3. Those results emphasize that the spoilage of CSS is very difficult to predict. Moreover, results have been obtained with bacterial groups co-inoculated in pair, in equicellular concentrations, but the spoilage process could be more complex in naturally contaminated products. Further investigations are needed to make 
progress in the understanding of antagonistic or cooperative interactions between the main bacterial species occurring in the spoilage flora of CSS. Knowledge of these interactions is of great importance for the potential development of novel preservation techniques and for the predictive microbiology of foods like CSS in which a mixed flora develops during storage and several microbial species contribute to spoilage. 


\section{References}

AFNOR, 1997. Normalisation française. Norme - Poissons transformés - Saumon fumé V45065.

AFNOR, 1987. Normalisation française. Analyse sensorielle. Directives générales pour l’implantation de locaux destinés à l'analyse sensorielle V09-105

Bourrain, M., Agogué, H., Leroi, F., Joffraud, J.J., Chevalier, F., Barbier, G., 2000. Bacterial population shifts during vacuum storage of cold-smoked salmon. Application of a molecular approach to describe communities of facultative anaerobes. Colloque " Microbiologie anaérobie ” de la Société Française de Microbiologie, 5-6 avril, Lyon, France.

Brillet, A., Pilet, M.F., Prevost, H., Bouttefroy, A., Leroi, F., 2004. Biodiversity of Listeria monocytogenes sensitivity to bacteriocin-producing Carnobacterium strains and application in sterile cold-smoked salmon. Journal of Applied Bacteriology 97,1029-1037.

Brillet, A., Pilet, M.F., Prevost, H., Leroi F., 2005. Effect of inoculation of Carnobacterium divergens V41, a biopreservative strain against Listeria monocytogenes risk, on the microbiological, chemical and sensory quality of cold-smoked salmon. International Journal of Food Microbiology 104, 309-324.

Cardinal, M., Gunnlaugsdottir, H., Bjoernevik, M., Ouisse, A., Vallet, J.L., Leroi F., 2004. Sensory characteristics of cold-smoked Atlantic salmon (Salmo salar) from European market and relationships with chemical, physical, and microbiological measurements. Food Research International 37, 181-193.

Conway, E.J., Byrne, A., 1933. An absorption apparatus for the micro-determination of certain volatile substances. I; The micro-determination of ammonia. Biochemical Journal 27, 419429.

Dalgaard, P., 1995. Qualitative and quantitative characterization of spoilage bacteria from packed fish. International Journal of Food Microbiology 26, 319-333.

Duffes, F., Leroi, F., Boyaval, P., Dousset, X., 1999. Inhibition of Listeria monocytogenes by Carnobacterium spp. strains in a simulated cold smoked fish system stored at $4^{\circ} \mathrm{C}$. International Journal of Food Microbiology 47,33-42.

de Man, J.C., Rogosa, M., Sharpe, M.E., 1960. A medium for the cultivation of Lactobacilli. Journal of Applied Bacteriology 23, 130-135.

Elliker, P.R., Anderson, A.W., Hannesson, G., 1956. An agar culture medium for lactic acid Streptococci and Lactobacilli. Journal of Dairy Science 39, 1611-1612.

Gardner, G.A., 1980. Brochothrix thermosphacta (Microbacterium thermosphactum) in the spoilage of meats. Psychrotrophic microorganisms in spoilage and pathogenicity 139-143.

Gonzalez-Rodriguez, M.N., Sanz, J.J., Santos, J.A., Otero, A., Garcia-Lopez, M.L., 2002. Numbers and types of microorganisms in vacuum-packed cold-smoked freshwater fish at the 
retail level. International Journal of Food Microbiology 77 (1/2), 161-168.

Gram, L., Huss, H.H., 1996. Microbiological spoilage of fish and fish products. International Journal of Food Microbiology 33, 121-137.

Gram, L., Ravn, L., Rash, M., Bartholin Bruhn, J., Christensen, A.B., Givskov, M., 2002. Food spoilage-interactions between food spoilage bacteria. International Journal of Food Microbiology 78, 79-97.

Joffraud, J.J., Leroi, F., Chevalier, F., 1998. Development of a sterile cold-smoked fish model. Journal of Applied Microbiology 85, 991-998.

Joffraud, J.J., Leroi, F., Roy, C., Berdagué, J.L., 2001. Characterisation of volatile compounds produced by bacteria isolated from the spoilage flora of cold-smoked salmon. International Journal of Food Microbiology 66, 175-184.

Jorgensen, L.V., Huss, H.H., Dalgaard, P., 2000a. The effect of biogenic amine production by single bacterial cultures and metabiosis on cold-smoked salmon. Journal of Applied Microbiology 89, 920-934.

Jorgensen, L.V., Dalgaard, P., Huss, H.H., 2000b. Multiple compound quality index for coldsmoked salmon (Salmo salar) developed by multivariate regression of biogenic amines and pH. Journal of Agricultural and Food Chemistry 48 (6), 2448-2453.

Jorgensen, L.V., Huss, H.H., Dalgaard, P., 2001. Significance of volatile compounds produced by spoilage bacteria in vacuum-packed cold-smoked salmon (Salmo salar) analyzed by GCMS and multivariate regression. Journal of Agricultural and Food Chemistry 49 (5), 23762381.

Leroi, F., Joffraud, J.J., 2000a. Salt and smoke simultaneously affect chemical and sensory quality of cold-smoked salmon during $5^{\circ} \mathrm{C}$ storage predicted using factorial design. Journal of Food Protection 63 (9), 1222-1227.

Leroi, F., Joffraud, J.J., Chevalier, F., 2000b. Effect of salt and smoke on the microbiological quality of cold smoked salmon during storage at $5^{\circ} \mathrm{C}$ as estimated by the factorial design method. Journal of Food Protection 63 (4), 502-508.

Leroi, F., Joffraud, J.J., Chevalier, F., Cardinal, M., 1998. Study of the microbial ecology of cold-smoked salmon during storage at $8^{\circ} \mathrm{C}$. International Journal of Food Microbiology 39, 111-121.

Leroi, F., Joffraud, J. J., Chevalier, F., Cardinal, M., 2001. Research of quality indices for coldsmoked salmon using a stepwise multiple regression of microbiological counts and physicochemical parameters. Journal of Applied Microbiology 90, 578-587..

Lyhs, U., Björkroth, J., Hyytiä, E., Korkeala, H., 1998. The spoilage flora of vacuum-packaged, sodium nitrite or potassium nitrate treated, cold-smoked rainbow trout stored at $4^{\circ} \mathrm{C}$ or $8^{\circ} \mathrm{C}$. International Journal of Food Microbiology 45, 135-142. 
Malakar, P.K., Barker, G.C., Zwietering, M.H., van't Riet, K., 2003. Relevance of microbial interactions to predictive microbiology. International Journal of Food Microbiology 84, 263272.

Malakar, P.K., Martens, D.E., Zwietering, M.H., Béal, C., van’t Riet, K., 1999. Modelling the interactions between Lactobacillus curvatus and Enterobacter cloacae. II. Mixed cultures and shelf life predictions. International Journal of Food Microbiology 51, 67-79.

Nilson, L., Hansen, T.B., Garrido, P., Buchrieser, C., Glaser, P., Knochel, S., Gram, L., Gravesen., A., 2005. Growth inhibition of Listeria monocytogenes by a non bacteriocinogenic Carnobacterium piscicola. Journal of Applied Microbiology 98, 172-183.

Paludan-Müller, C., Dalgaard, P., Huss, H.H., Gram, L., 1998. Evaluation of the role of Carnobacterium piscicola in spoilage of vacuum and modified atmosphere-packed-smoked salmon stored at $5^{\circ} \mathrm{C}$. International Journal of Food Microbiology 39, 155-166.

Stohr, V., Joffraud, J.J., Cardinal, M., Leroi, F., 2001. Spoilage potential and sensory profile associated with bacteria isolated from cold-smoked salmon. Food Research International 34, 797-806.

Truelstrup Hansen, L., Røntved, S.D., Huss, H.H., 1998. Microbiological quality and shelf life of cold-smoked salmon from three different processing plants. Food Microbiology 15, 137150 .

Truelstrup Hansen, L., Gill, T., Røntved, S.D., Huss, H.H., 1996. Importance of autolysis and microbiological activity on quality of cold-smoked salmon. Food Research International 29 (2), 181-188.

Truelstrup Hansen, L., Gill, T., Huss, H.H., 1995. Effects of salt and storage temperature on chemical, microbiological and sensory changes in cold-smoked salmon. Food Research International 28 (2), 123-130.

Truelstrup Hansen L., Huss, H.H., 1998. Comparison of the microflora isolated from spoiled cold-smoked salmon from three smokehouses. Food Research International 31 (10), 703-711.

van Spreekens, K.J.A., 1974. The suitability of a modification of Long and Hammer's medium for the enumeration of more fastidious bacteria from fresh fisheries products. Archiv für Lebensmittelhygiene 25, 213-219.

Vaz-Velho, M., Todorov, S., Ribeiro, J., Gibbs, P., 2005. Growth control of Listeria innocua 2030c during processing and storage of cold-smoked salmon-trout by Carnobacterium divergens V41 culture and supernatant. Food Control 16 (6), 540-548.

Ward, D.R., 2001. Description of the Situation. Journal of Food Science, Supplement to volume 66 (7), 1067-1071.

Wasney, M.A., Holley, R.A., Jayas, D.S., 2001. Cresol Red Thallium Acetate Sucrose Inulin 
(CTSI) agar for the selective recovery of Carnobacterium spp. International Journal of Food Microbiology 64, 167-174.

Yamazaki, K., Suzuky, M., Kawai, Y., Inoue, N., Montville, T.J., 2003. Inhibition of Listeria monocytogenes in cold-smoked salmon by Carnobacterium piscicola CS526 isolated from frozen surimi. Journal of Food Protection 66,1420-1425 
Table 1

Bacterial strains (reference numbers in IFREMER collection) inoculated as pure or mixed cultures in cold-smoked salmon for the different sets of trials.

\begin{tabular}{|c|c|c|c|}
\hline Inoculation trials & Set & Inoculated strain & Label \\
\hline Trial 1 & $\begin{array}{l}\text { Set A } \\
\text { Pure cultures }\end{array}$ & $\begin{array}{l}\text { Control } \\
\text { Brochothrix thermosphacta: (SF 674, SF 677, SF 678, SF 713, SF 712) } \\
\text { Serratia liquefaciens-like: (SF 1460, SF 1461, SF 1467, SF 1463, SF 1464) } \\
\text { Carnobacterium piscicola: (SF 644, SF 692) } \\
\text { Photobacterium phosphoreum: (SF 680, SF 686, SF 684, SF 714, SF 723) } \\
\text { Lactobacillus sakei: (SF 811, SF 696, SF 699, SF 841, SF 771) } \\
\text { Vibrio sp.: (SF 1766, SF 1803, SF 1805, SF 1813, SF 1816) }\end{array}$ & $\begin{array}{l}\text { T } \\
\text { B } \\
\text { S } \\
\text { C } \\
\text { P } \\
\text { L } \\
\text { V }\end{array}$ \\
\hline & $\begin{array}{l}\text { Set B } \\
\text { Mixed cultures }\end{array}$ & $\begin{array}{l}\text { Control } \\
\text { Lactobacillus sakei/ Carnobacterium piscicola } \\
\text { Lactobacillus sakei/ Brochothrix thermosphacta } \\
\text { Lactobacillus sakei/ Serratia liquefaciens-like } \\
\text { Carnobacterium piscicola/ Brochothrix thermosphacta } \\
\text { Carnobacterium piscicola/ Serratia liquefaciens-like }\end{array}$ & $\begin{array}{c}\mathrm{T} \\
\mathrm{L} / \mathrm{Ca} \\
\mathrm{L} / \mathrm{B} \\
\mathrm{L} / \mathrm{S} \\
\mathrm{C} / \mathrm{B} \\
\mathrm{C} / \mathrm{S}\end{array}$ \\
\hline Trial 2 & $\begin{array}{l}\text { Set C } \\
\text { Pure cultures }\end{array}$ & $\begin{array}{l}\text { Control } \\
\text { Carnobacterium piscicola } \\
\text { Photobacterium phosphoreum } \\
\text { Lactobacillus sakei } \\
\text { Vibrio sp. }\end{array}$ & $\begin{array}{l}\mathrm{T} \\
\mathrm{C} \\
\mathrm{P} \\
\mathrm{L} \\
\mathrm{V}\end{array}$ \\
\hline & $\begin{array}{l}\text { Set D } \\
\text { Mixed cultures }\end{array}$ & $\begin{array}{l}\text { Control } \\
\text { Lactobacillus sakei/ Carnobacterium piscicola } \\
\text { Lactobacillus sakei/ Photobacterium phosphoreum } \\
\text { Lactobacillus sakei /Vibrio sp. } \\
\text { Carnobacterium piscicola/ Photobacterium phosphoreum } \\
\text { Carnobacterium piscicola/Vibrio sp. }\end{array}$ & $\begin{array}{c}\mathrm{T} \\
\mathrm{L} / \mathrm{Cb} \\
\mathrm{L} / \mathrm{P} \\
\mathrm{L} / \mathrm{V} \\
\mathrm{C} / \mathrm{P} \\
\mathrm{C} / \mathrm{V}\end{array}$ \\
\hline
\end{tabular}


Table 2

Characteristic odours of spoiled cold-smoked salmon, description and chemical reference

\begin{tabular}{ccc}
\hline Categories of odour & Label & Description and associated molecules \\
\hline No specific odour & nso & No note other than smoke or raw fish odour \\
Grass / green & grass & Odours from freshly cut grass (hexanal) \\
Fruity / plastic & fru & Odour of citrus fruit or plastic (nonylaldehyde or decylaldehyde) \\
Butter & butt & Odour developed by fresh butter (diacetyl) \\
Feet/cheese & feet & Odour of feet (isovaleraldehyde) \\
Amine / sour / vinegar & amin & Odour related to urine or curdled milk or vinegar \\
Sulphur & sulph & Odrimethylamine for amine) \\
& & \\
& & (dimethylsulphide, thiobarbituric acid) \\
\hline
\end{tabular}


Table 3

Spoilage potential of bacterial groups inoculated in pure (diagonal) or mixed culture in cold-smoked salmon and stored at $8^{\circ} \mathrm{C}$ under vacuum. $(-)$ : no spoiling ; (+) light spoiling ; (++) strong spoiling potential. $(\uparrow),(\downarrow),(\rightarrow)$, indicate that spoilage potential is enhanced, decreased or similar, respectively, when compared to the highest spoiler bacterial group of the association.

\begin{tabular}{lllllll}
\hline Bacterial group & L. sakei & C. piscicola & B. thermosphacta & Vibrio sp. & P. phosphoreum & S. liquefaciens-like \\
\hline L. sakei & ++ & $+(\downarrow)$ & $++(\downarrow)$ & $++(\rightarrow)$ & $+(\downarrow)$ & $+(\downarrow)$ \\
C. piscicola & & + & $+(\uparrow)$ & $++(\uparrow)$ & $+(\rightarrow)$ & $++(\rightarrow)$ \\
B.thermosphacta & & & + & & & \\
Vibrio sp. & & & & & \\
P. phosphoreum & & & & & + \\
S. liquefaciens-like & & & & & + \\
\end{tabular}



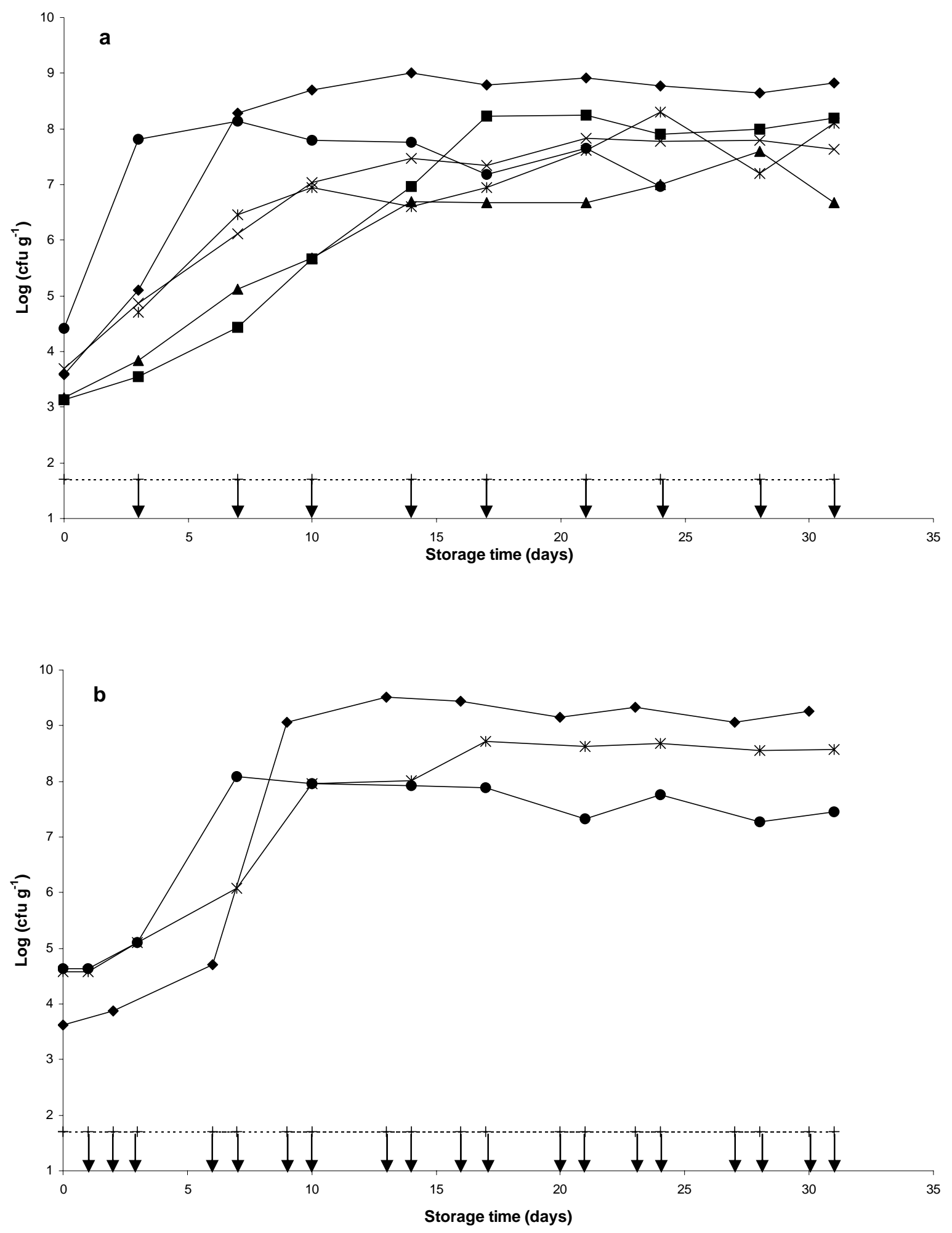

Fig. 1. Bacterial growth of pure cultures inoculated in vacuum-packed cold-smoked salmon stored at $8^{\circ} \mathrm{C}$. a: Trial 1 , set A; b: Trial 2, set C. $(\bullet)$ : Lactobacillus sakei; $(\bullet)$ : Serratia liquefaciens-like; $(\mathbf{\Delta})$ : Brochothrix thermosphacta; $(\times)$ : Photobacterium phosphoreum; $(*)$ : Carnobacterium piscicola; $(\bullet)$ : Vibrio sp; (+) : Control, no colony being detected, the symbol " $\downarrow$ “ indicates that counts are below the detection threshold. 

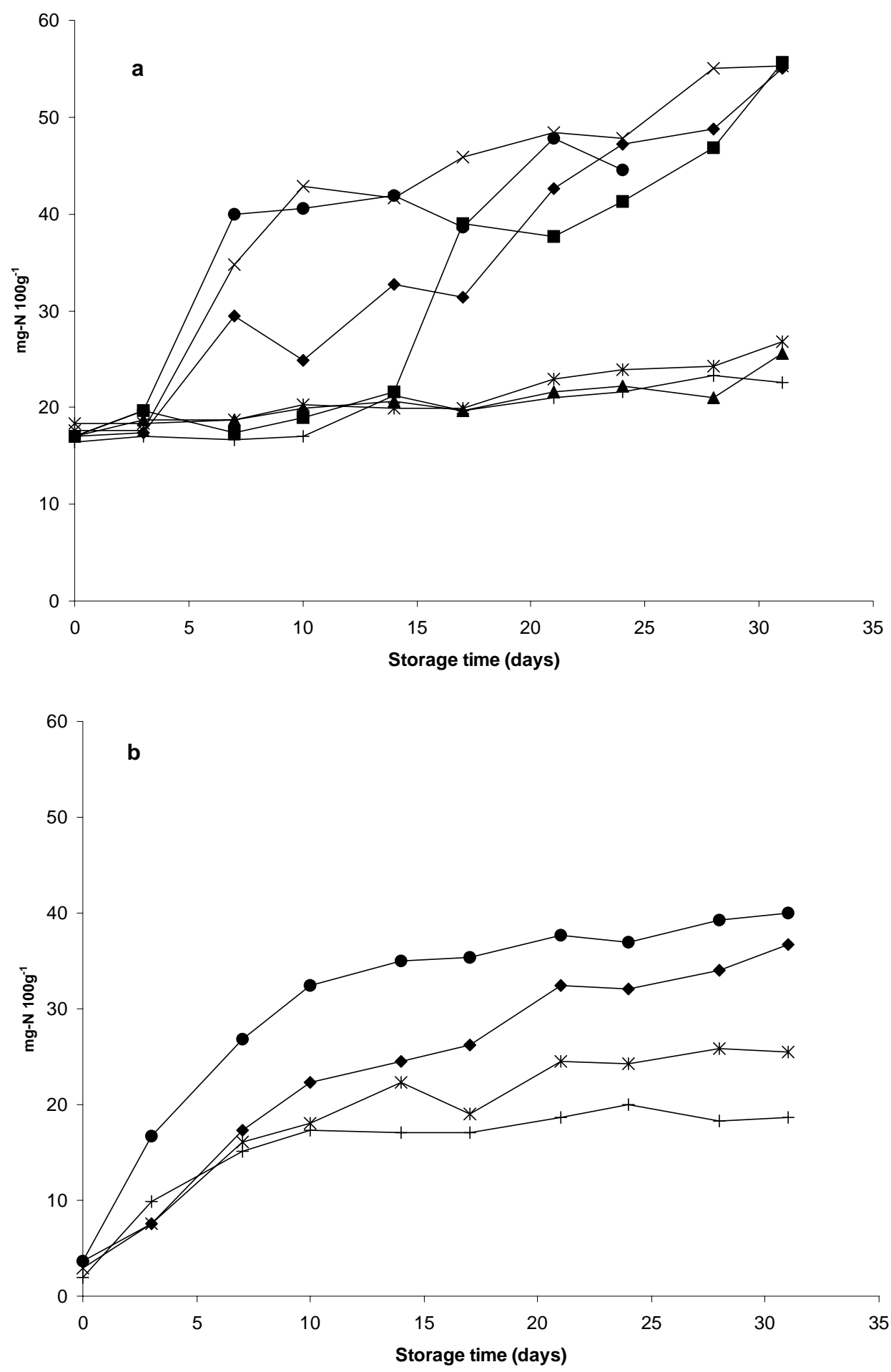

Fig. 2. Total volatile base nitrogen production of pure cultures inoculated in vacuum-packed coldsmoked salmon stored at $8^{\circ} \mathrm{C}$. a: Trial 1 , set A; b: Trial 2 , set C

$(+)$ : Control; $(\bullet)$ : Lactobacillus sakei; $(\bullet)$ : Serratia liquefaciens-like; $(\mathbf{\bullet})$ : Brochothrix thermosphacta; $(\times)$ : Photobacterium phosphoreum; $(*)$ : Carnobacterium piscicola; $(\bullet)$ : Vibrio sp. 


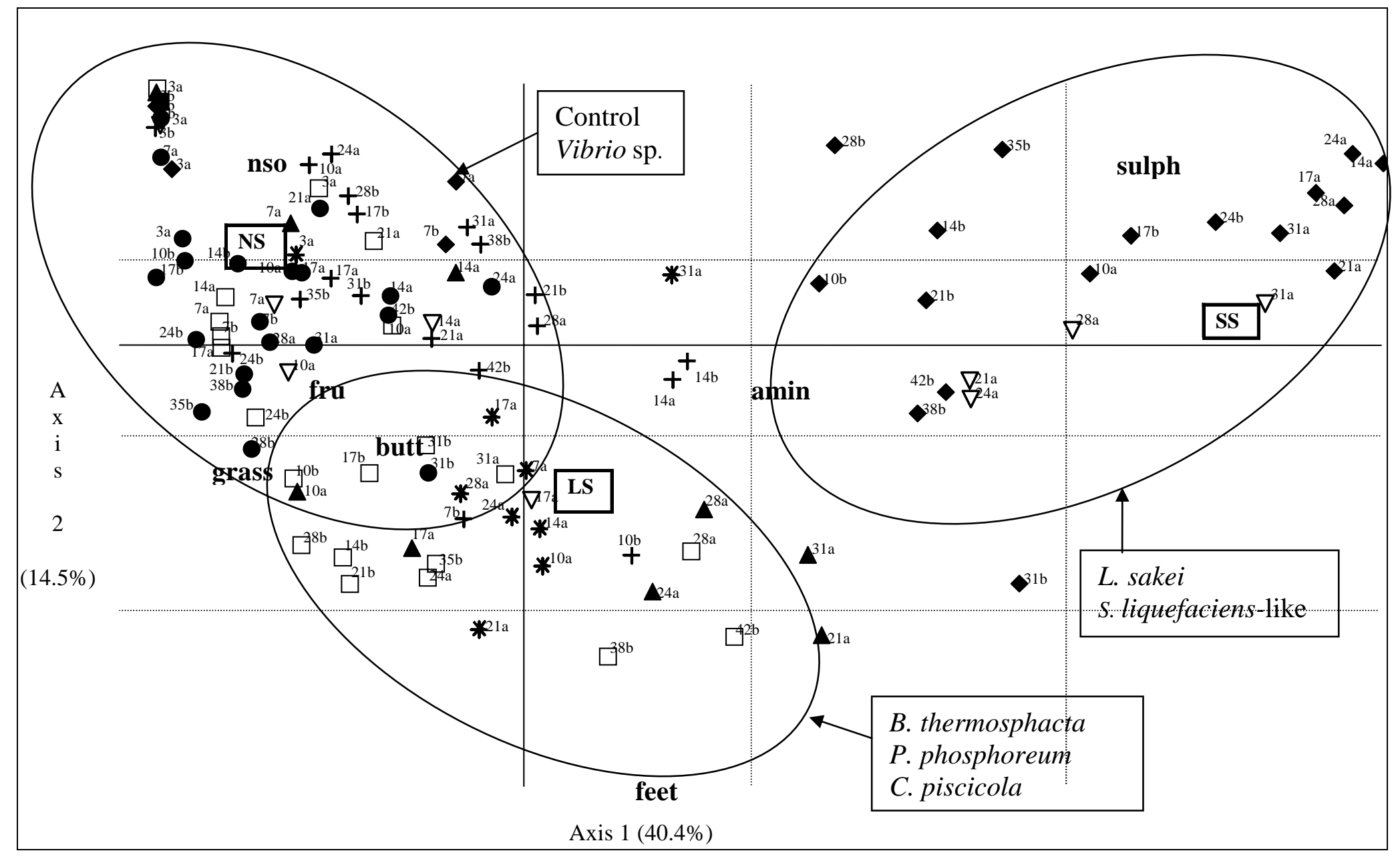

Fig. 3. Simultaneous loading of pure cultures, sensory descriptors and spoilage levels on the plane 1-2 of correspondence express duration of storage (in days); a: first trial, b: second trial. (NS): non spoiled; (LS): lightly spoiled; (SS): strongly spoiled. (•) : Control; ( $\mathbf{\Lambda})$ : Brochothrix thermosphacta; $(\square)$ : Carnobacterium piscicola; $(+)$ : Vibrio sp; $(*)$ : Photobacterium phosphoreum; $(\nabla)$ : Serratia liquefaciens-like; $(\bullet)$ : Lactobacillus sakei 

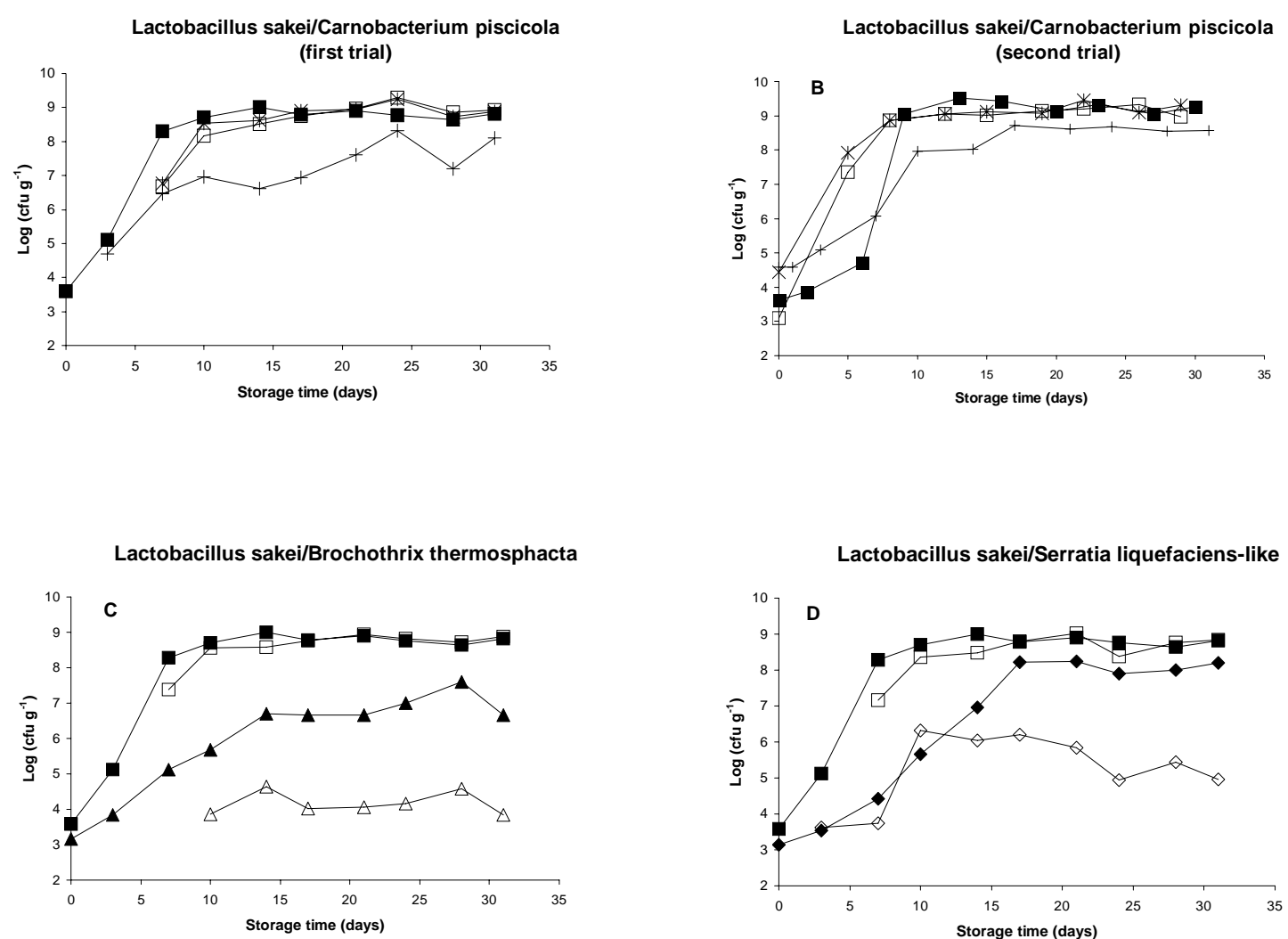

Lactobacillus sakei/Photobacterium phosphoreum
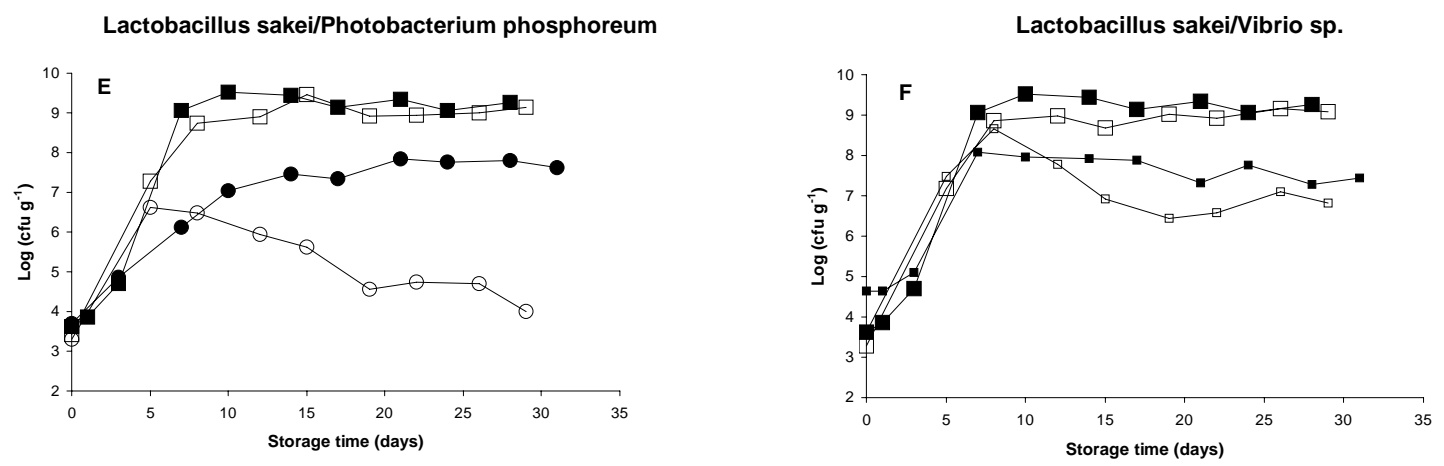

Fig. 4. Growth of the different bacterial groups in pure and mixed cultures with Lactobacillus sakei inoculated in vacuum-packed cold-smoked salmon stored at $8^{\circ} \mathrm{C}$.

$(\boldsymbol{\square}, \square)$ : Lactobacillus sakei; $(\bullet, \diamond)$ : Serratia liquefaciens-like; $(\boldsymbol{\Lambda}, \triangle)$ : Brochothrix thermosphacta; $(\bullet, \bigcirc)$ : Photobacterium phosphoreum; $(\mathbf{\square}, \square)$ : Vibrio sp.; (full symbol: pure culture; empty symbol: mixed culture); $(+)$ : Carnobacterium piscicola (pure culture); $(*)$ : Carnobacterium piscicola + Lactobacillus sakei. 
Carnobacterium piscicola/Brochothrix thermosphacta

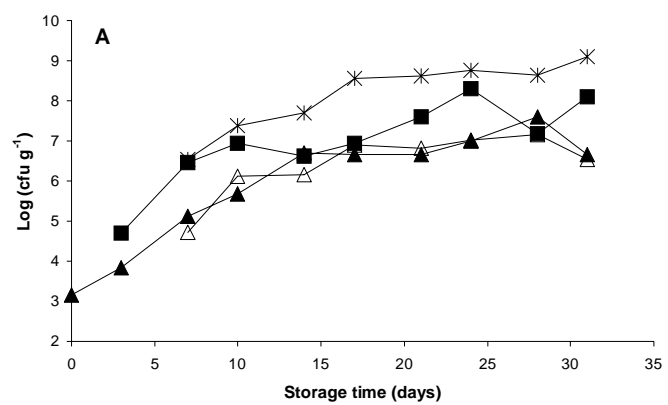

Carnobacterium piscicola/Photobacterium phosphoreum

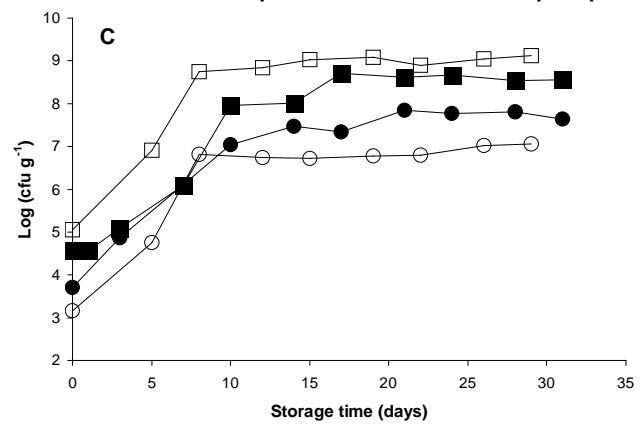

Carnobacterium piscicola/Serratia liquefaciens-like

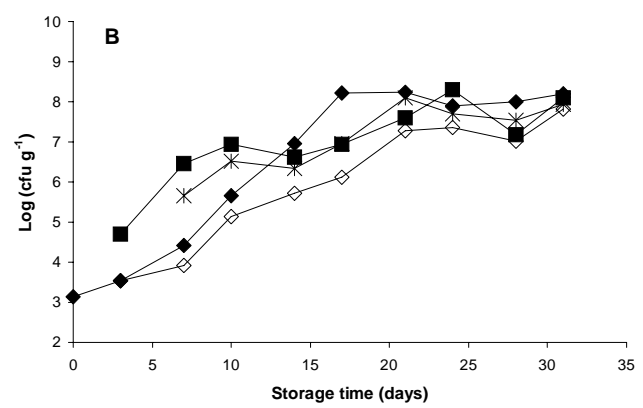

Carnobacterium piscicola/Vibrio sp.

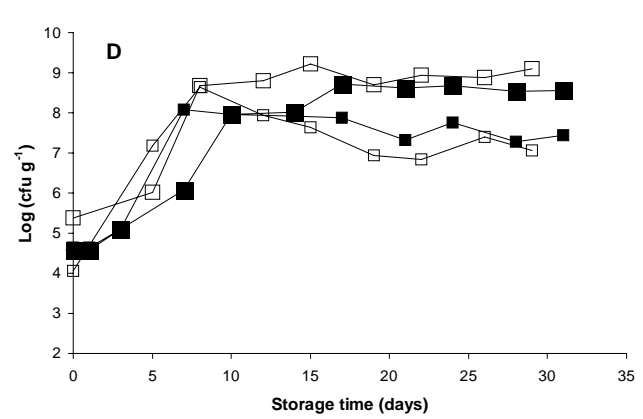

Fig. 5. Growth of the different bacterial groups in pure and mixed cultures with Carnobacterium piscicola inoculated in vacuum-packed cold-smoked salmon stored at $8^{\circ} \mathrm{C}$.

$(\diamond, \diamond)$ : Serratia liquefaciens-like; $(\boldsymbol{\Lambda}, \triangle)$ : Brochothrix thermosphacta; $(\boldsymbol{\bullet}, \bigcirc)$ : Photobacterium phosphoreum; $(\boldsymbol{\square}, \square)$ : Vibrio sp.; $(\mathbf{\square}, \square)$ : Carnobacterium piscicola; (full symbol: pure culture; empty symbol: mixed culture); (*):Carnobacterium piscicola + Lactobacillus sakei. 


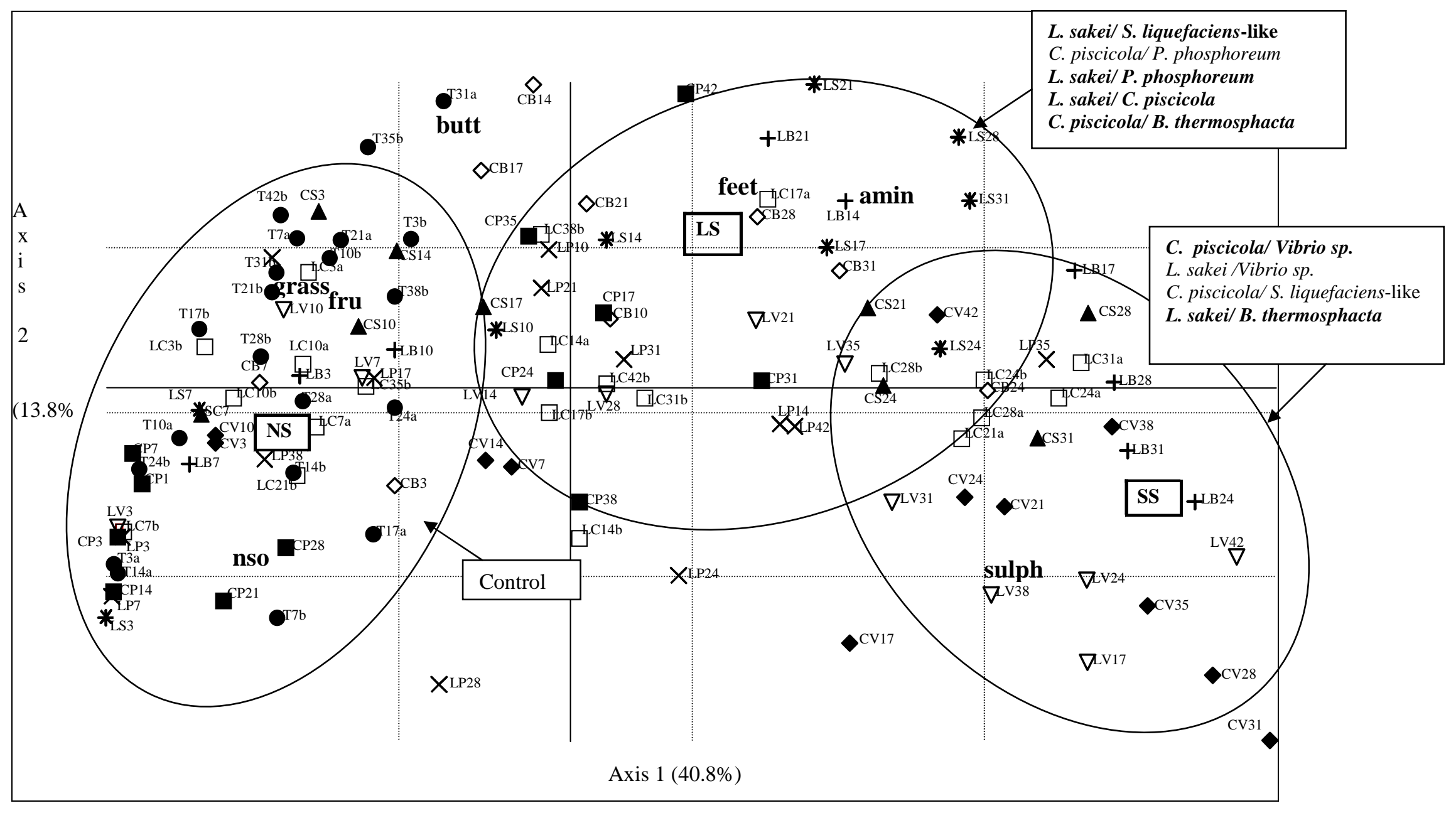

Fig. 6. Simultaneous loading of mixed cultures, sensory descriptors and spoilage levels on the plane 1-2 of correspondence factorial analysis (CFA). Numbers express duration of storage (in days); a: first trial, b: second trial. (NS): non spoiled; (LS): lightly spoiled; (SS): strongly spoiled. Mixed cultures showing an interaction are expressed in bold characters. $(\bullet)$ : Control; ( $\square)$ : Lactobacillus sakei/ Carnobacterium piscicola; (+): Lactobacillus sakei/ Brochothrix thermosphacta; (*): Lactobacillus sakei/ Serratia liquefaciens-like; (×): Lactobacillus sakei/ Photobacterium phosphoreum; $(\nabla)$ : Lactobacillus sakei Nibrio sp.; $(\diamond)$ : Carnobacterium piscicola/ Brochothrix. thermosphacta; $(\boldsymbol{\Delta})$ : Carnobacterium piscicola/ Serratia liquefaciens-like; (ロ): Carnobacterium piscicola/ Photobacterium phosphoreum; $(\bullet)$ : Carnobacterium piscicola/ Vibrio sp. 